\title{
Serpentinite Slurries against Forest Fires
}

\author{
R. D. Schuiling \\ Institute of Geosciences, Utrecht University, Utrecht, The Netherlands \\ Email: schuiling@geo.uu.nl
}

Received 8 February 2015; accepted 7 March 2015; published 12 March 2015

Copyright (C) 2015 by author and Scientific Research Publishing Inc.

This work is licensed under the Creative Commons Attribution International License (CC BY). http://creativecommons.org/licenses/by/4.0/

(c) (i) Open Access

\begin{abstract}
Forest fires are one of the commonest natural hazards. Forest fires make the largest contribution to $\mathrm{CO}_{2}$ emissions after the burning of fossil fuels. Here a new technology is proposed to extinguish forest fires not with water, but with a slurry of serpentine. Serpentinites are abundantly available in many countries on every continent. If serpentine is calcined, it weathers very fast and captures $\mathrm{CO}_{2}$. Calcination, however, requires a lot of heat, which makes it counterproductive to produce calcined serpentine for $\mathrm{CO}_{2}$ capture. In cases, however, where heat is the problem, like in forest fires, one can extinguish them to greater advantage by using serpentinite slurries instead of plain water. The calcined residue that is left as a thin cake on the burning material prevents oxygen to reach the burning material. It also prevents the escape of inflammable gases, and the calcination itself withdraws large quantities of heat from the fire. After the fire is extinguished, the calcined material in contact with the atmosphere will rapidly weather and capture $\mathrm{CO}_{2}$. This compensates part of the $\mathrm{CO}_{2}$ that is produced by the fire. In tests, where the efficacy of quenching fires with serpentine slurries was compared to the effect of water, it turned out that serpentinite slurries performed far better.
\end{abstract}

\section{Keywords}

Forest Fires, Calcination, Endothermic Reaction, Serpentinite Slurries, $\mathrm{CO}_{2}$ Capture

\section{Introduction}

Rising $\mathrm{CO}_{2}$ levels in the atmosphere are considered by many to cause a climate change. Their role in causing ocean acidification is unambiguous. The Earth is continuously degassing, and $\mathrm{CO}_{2}$ is emitted by volcanoes and by the dissociation of limestones carried to great depth in subduction zones (Schuiling, 2004). There must exists an efficient feedback system, otherwise the Earth atmosphere and climatic conditions would be like on Venus, which has an atmosphere of 85 bars $\mathrm{CO}_{2}$ pressure, and a surface temperature of $460^{\circ} \mathrm{C}$. This feedback mechanism is the weathering of basic silicates, which can take place on Earth thanks to the presence of liquid water, which is lacking on Venus. 
The natural choice for the best method to counteract climate change and ocean acidification is mineral carbonation (Schuiling and Krijgsman, 2006). During the reaction of basic silicates with carbonic acid and water (a process known as weathering), $\mathrm{CO}_{2}$ is transformed into bicarbonate ions. The bicarbonate solutions are carried by rivers to sea, where they form carbonate sediments (limestones and dolomites). These carbonates represent the ultimate and sustainable storage of $\mathrm{CO}_{2}$ (Figure 1).

During the entire geological history, volcanoes on Earth have emitted $\mathrm{CO}_{2}$. Weathering has kept the $\mathrm{CO}_{2}$ levels of the atmosphere within reasonable and livable bounds. There have been fluctuations, depending on the rate of geological processes like mountain building and volcanism (Raymo and Ruddiman, 1992), but the advantage of weathering is that it has an inbuilt negative feedback. The higher the $\mathrm{CO}_{2}$ pressure in the atmosphere, the more acid the waters in equilibrium with this atmosphere, and the faster the rate of weathering by which atmospheric $\mathrm{CO}_{2}$ levels are reduced. At present, by burning in a few hundred years the fossil fuels that have taken hundreds of millions of years to form, the $\mathrm{CO}_{2}$ level of the atmosphere is rapidly rising and the oceans are acidifying, because the weathering process cannot keep pace with the greatly increased $\mathrm{CO}_{2}$ emission, which is 30 to 60 times larger than the natural emission of $\mathrm{CO}_{2}$.

Olivine and serpentine weather easily and are abundantly available, close to the surface, where they can be mined in open-pit mines. By milling these rocks, and spreading the crushed material over land, shallow sea and beaches, the process of weathering can be enhanced, leading to a new balance between emission and capture (Schuiling et al., 2011). Next to these major applications, minerals like olivine or serpentine can serve the same purpose in a number of niche applications. One such niche application is the use of serpentine slurries to quench fires. The residual solids weather fast and capture $\mathrm{CO}_{2}$. This compensates for the $\mathrm{CO}_{2}$ that is produced during the fire. This way quenching forest fires with serpentine slurries becomes an environmental technology that can help to manage the climate. The environment not only provides the material to be used, but also imposes the conditions under which it will be applied (Schuiling, 1998).

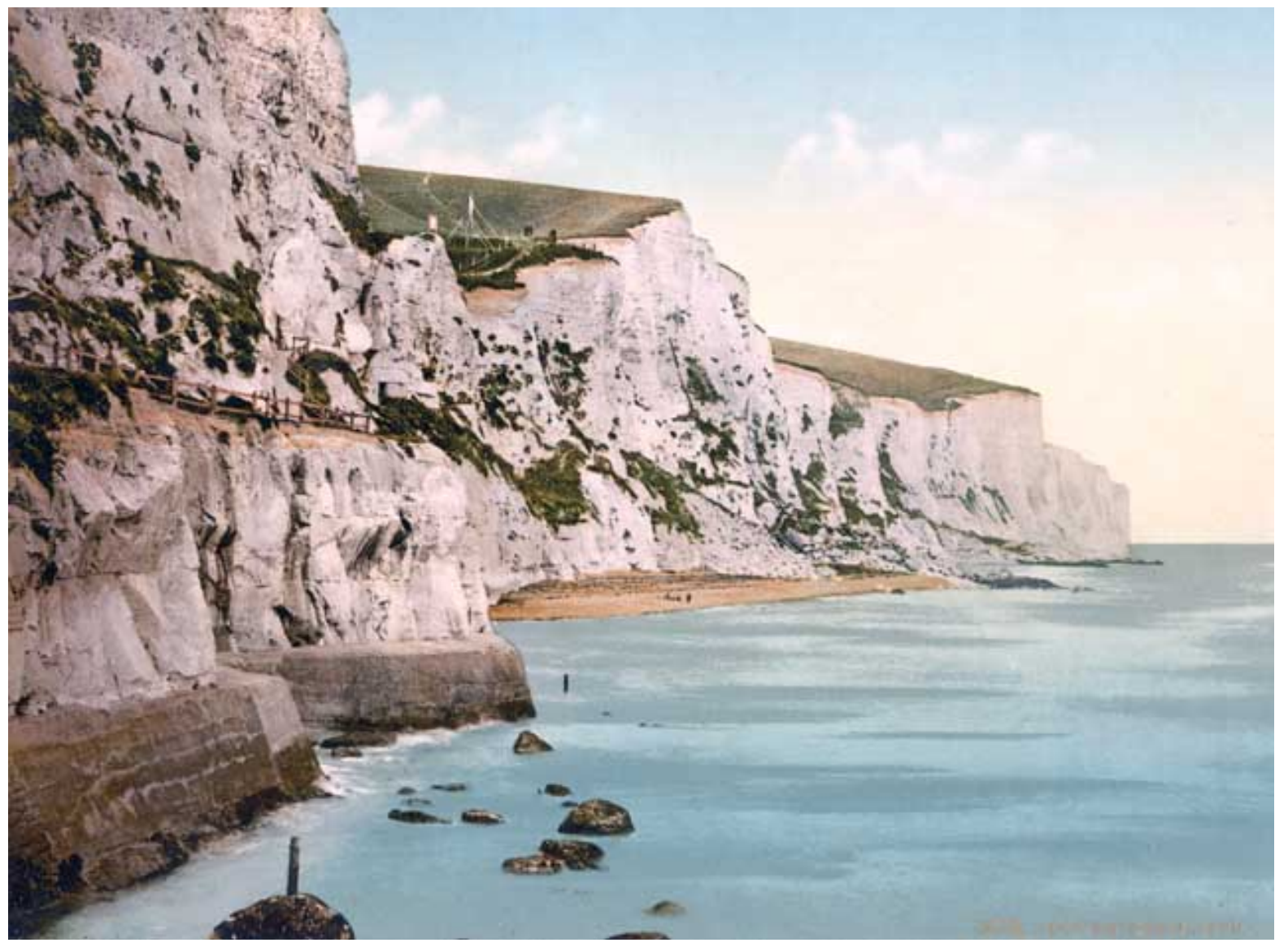

Figure 1. The cliffs of Dover are one of the places where nature has stored its $\mathrm{CO}_{2}$. 


\section{Study Approach}

\subsection{Heat Withdrawal}

If one knows the heat capacity of water and serpentine as a function of temperature (Robie et al., 1978), it is straightforward to calculate the total heat that is withdrawn from a fire when a certain volume of a mixture of serpentine and water is sprayed over it. One needs, of course, also take into account the heats of vaporization of the water, and the heat of dissociation of the serpentine. The last can be calculated if the mineralogical composition of the end-product is known. Equilibrium phases would be olivine, enstatite and water vapor, but in reality this equilibrium is not reached in the short period in the fire, but rather some more or less amorphous or poorly crystalline intermediate materials. This means that the calculated heat of dissociation should be increased by an unknown, but rather modest amount equivalent to the difference in heat content between crystalline compounds and their amorphous equivalents. This makes serpentine slightly more efficient than would follow from the equilibrium calculation, where data for crystalline materials and pure water were used. Mixes of $40 \mathrm{wt} \%$ of serpentine and $60 \%$ of water are still quite liquid and easy to pump. The total heat withdrawn by this mixture when heated from room temperature to $900 \mathrm{~K}$ was compared to that of pure water over the same temperature interval. It turns out that the serpentine slurry withdraws $27 \%$ more heat than an equivalent volume of water.

\subsection{Quenching Tests}

Several quenching tests were carried out at the test site of Brand beveiliging (Fire Protection) BV in Wijchen/the Netherlands to observe the effects of spraying fires with serpentine slurries, and compare these to quenches with water. It was found that fires were considerably faster quenched with serpentinite than with water. With serpentine slurries, the effect was quasi-immediate. Moreover, a fire quenched with water had the tendency to repeatedly start flaming again after the spraying was stopped. This is obvious in tv reports on large forest fires that are sprayed with water. In contrast, fires that were sprayed with serpentinite slurries were quenched permanently. For this experiment, serpentine powder from a serpentinite quarry near Leoben (Austria) was used. A previous quenching test was carried out with a serpentine-rich residue from the PASEK olivine mine in NW Spain, with similar results.

The difference in behavior of fires when quenched with either water of serpentinite slurries is certainly not entirely due to their different heat content. It was observed that the serpentinite covers the burning material with a thin baked layer. This skin prevents the escape of inflammable gases and the access of oxygen, and this effect is more important than the larger heat withdrawal. After the fire is quenched, this thin baked layer will rapidly dissolve, while it reacts very fast with $\mathrm{CO}_{2}$ and rainwater.

\subsection{After the Fire}

Once the fire is quenched, a baked serpentine residue is left. This is very reactive to mixtures of $\mathrm{CO}_{2}$ and water. Experiments with calcined serpentine that was alternately shaken in a closed bottle, and left standing open to the air showed that the reaction with water, and the absorption of $\mathrm{CO}_{2}$ was much more intense than the same treatment with fine-grained olivine. In fact, when calcined serpentine powder was first brought in contact with water, the $\mathrm{pH}$ rose within 5 minutes to 9.6 (Figure 2).

This is another major advantage of the use of serpentine slurries, they compensate rapidly a significant part of the $\mathrm{CO}_{2}$ that was emitted by the fire. An additional beneficial effect may be the release of magnesium, increasing the soil $\mathrm{pH}$ and helping trees to grow faster.

\section{Results and Discussion}

\subsection{Applications}

Possibly the best use of serpentinite slurries would be in forest fires, both on the ground as from the air. Dropping a load of serpentinite slurries from a plane or helicopter has the advantage that the slurry can have a higher percentage of serpentine than when it must be pumped, because for dropping a higher viscosity is permitted, as even a more viscous mud can be scooped out of a basin.

Another type of fire where the application of serpentine slurries might come in useful is in tunnels. 


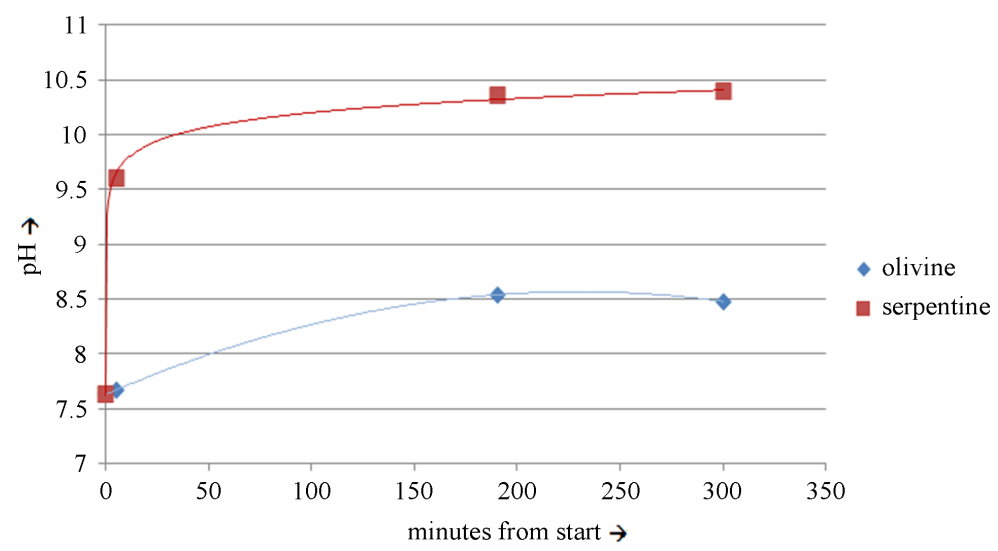

Figure 2. $\mathrm{pH}$ increase of suspensions of calcined serpentine and fine grained olivine.

\subsection{Global $\mathrm{CO}_{2}$ Emissions from Forest Fires}

The global $\mathrm{CO}_{2}$ emissions from forest fires are considerable. It is difficult to obtain data on how much $\mathrm{CO}_{2}$ is annually emitted by forest fires. There are some data from the USA, where it was calculated that the $\mathrm{CO}_{2}$ emission by bush fires was between $4 \%$ and $6 \%$ of the total $\mathrm{CO}_{2}$ emission from fossil fuels in the USA (Thompson, 2007), which would mean about 275 million tons. This is of the same order as the total $\mathrm{CO}_{2}$ emissions by traffic in the USA. Liu Yongqiang et al. 2011, arrive at a lower estimate of 90 million tons. A study for boreal Eurasia (Shvidenko et al., 2011) arrives at 440 million tons of $\mathrm{CO}_{2}$ emissions annually from forest fires in boreal Eurasia. It is difficult to extrapolate these data to the whole world, but it is likely that the total of $\mathrm{CO}_{2}$ emissions from forest fires will exceed $3 \mathrm{Gt}$ of $\mathrm{CO}_{2}$, as the largest contributions are from savannah fires in Africa, and forest fires in S America and SE Asia. In fact, Van der Werf et al., 2009 estimate that forest fires worldwide contribute $20 \%$ of global $\mathrm{CO}_{2}$ emissions, making it the second largest source after the burning of fossil fuels, but their estimate includes forest losses by deforestation.

If fire fighting by the use of serpentine slurries instead of water could save $10 \%$ of the forests lost by fire, this would mean a reduction in the order of 300 million tons of $\mathrm{CO}_{2}$ emitted annually. For the total reduction in $\mathrm{CO}_{2}$ emission one should add the amount of $\mathrm{CO}_{2}$ that is rapidly captured by the serpentine after it was calcined in the fires.

Using the common and cheap natural material serpentine instead of expensive fire retardants like diammonium phosphate which contributes nothing to $\mathrm{CO}_{2}$ capture is an obvious improvement over current fire fighting practice.

In countries with a warm and dry season, and frequent forest fires in summer, small permanent basins (ponds) should be constructed near large forests, where serpentine slurries are kept ready for emergencies. Another advantage in countries with a shortage of water is the fact that quenching with serpentinite slurries needs much less water than quenching with water only.

\section{Conclusion}

Serpentine slurries provide a cheap and effective environmental technology to quench widespread fires. Likely applications are in forest fires or tunnel fires. After the fire is ended, the baked residue of the serpentine dissolves fast by reaction with $\mathrm{CO}_{2}$ and water. By this reaction the greenhouse gas $\mathrm{CO}_{2}$ is converted to, and stored as innocent bicarbonate solutions. This compensates the $\mathrm{CO}_{2}$ that was emitted by the fire. The reduction of the number and extent of forest fires by using serpentine slurries to extinguish them together with the $\mathrm{CO}_{2}$ compensation by the rapid weathering of the calcined serpentine can lead to a significant reduction in global $\mathrm{CO}_{2}$ emissions. $\mathrm{CO}_{2}$ reduction is not the only advantage of this approach; it probably will save lives as well.

\section{Acknowledgements}

Thanks are due to J. van Ooij, K. Sickmann and M. Warnar, who participated in this research as part of their ju- 
nior thesis at the Junior College Utrecht. I also wish to thank Javier Martinez Rubio from the PASEK olivine mine (Spain), and Jan Koller from the Isomag serpentinite quarry (Austria) for making serpentine samples available.

\section{References}

Liu, Y. Q., Stanturf, J., Tian, H. Q., \& Qu, J. (2011). CO2 Emissions from Wildfires in the U.S. Present Status and Future Trends.

Raymo, M. E., \& Ruddiman, W. F. (1992). Tectonic Forcing of Late Cenozoic Climate. Nature, 359, 117-121. http://dx.doi.org/10.1038/359117a0

Robie, R. A., Hemingway, B. S., \& Fisher, J. R. (1978). Thermodynamic Properties of Minerals and Related Substances at 298.15 K and 1 Bar (105 Pascals) Pressure and at Higher Temperatures. Geological Survey Bulletin, 1452, 456 p.

Schuiling, R. D. (1998). Geochemical Engineering: Taking Stock. Journal of Geochemical Exploration, 62, 1-28. http://dx.doi.org/10.1016/S0375-6742(97)00042-3

Schuiling, R. D. (2004). Thermal Effects of Massive $\mathrm{CO}_{2}$ Emissions Associated with Subduction Volcanism. Comptes Rendus Geoscience, 336, 1053-1059. http://dx.doi.org/10.1016/j.crte.2004.04.008

Schuiling, R. D., Tickell, O., \& Wilson, S. A. (2011). Climate Change and the KISS Principle. Poster Goldschmidt Conference Prague, 14-19 August 2011.

Schuiling, R. D. and Krijgsman, P. (2006). Enhanced Weathering; an Effective and Cheap Tool to Sequester $\mathrm{CO}_{2}$. Climatic Change, 74, 349-354. http://dx.doi.org/10.1007/s10584-005-3485-y

Shvidenko, A., Schepaschenko. D., Sukhinin, A., McCallum, I., \& Maksyutov, S. (2011). Carbon Emissions from Forest Fires in Boreal Eurasia between 1998-2010. The 5th International Wildland Fire Conference, South Africa.

Thompson, A. (2007). Wildfires Release as Much $\mathrm{CO}_{2}$ as Cars. Live Science.

Van der Werf, G. R., Morton, D. C., DeFries, R. C., Olivier, J. G. J., Kasibhatla, P. S., Jackson, R. B., Collatz, G. J., \& Randerson, J. T. (2009). $\mathrm{CO}_{2}$ Emissions from Forest Loss. Nature Geoscience, 2, 737-738. http://dx.doi.org/10.1038/ngeo671 